\title{
FORMAÇÃO DOCENTE EM PORTUGUÊS, LÍNGUA DE ACOLHIMENTO INDÍGENA: ASPECTOS E PARTICULARIDADES DO ENSINO PARA OS POVOS ORIGINÁRIOS DO BRASIL
}

\author{
UMBERTO EUZEBIO \\ Universidade de Brasília (UNB), Brasília, Distrito Federal, Brasil
}

\begin{abstract}
Resumo: A Língua de Acolhimento é caracterizada por estar inserida no contexto migratório, fazendo o elo entre o afetivo e a integração de pessoas em vulnerabilidade para o aprendizado emergencial. Como fundamentação teórica, este trabalho está alicerçado em Ançã (2008), Grosso (2010), Cabete (2010), Amado (2013), Barbosa e São Bernardo (2017). O objetivo foi analisar e refletir sobre a formação de professores para Ensino de Português como Língua de Acolhimento Indígena e verificar a adequação dessa terminologia a partir de um Projeto de Extensão com estudantes indígenas e não indígenas. Foi aplicada a metodologia da escuta sensível de Barbier (2007) e, como resultados, conclui-se que as práticas voltadas para povos indígenas possibilitam adequar o termo para esse uso, uma vez que a condição indígena se adequa a este contexto.
\end{abstract}

PalavRas-chave: Indígena. L2. Formação Docente. Português.

\section{INTRODUÇÃO E CARACTERIZAÇÃO}

No início do século XXI, o governo brasileiro implantou a política de ações afirmativas para indígenas, possibilitando o ingresso de estudantes indígenas em universidades públicas federais, dentre elas na Universidade de Brasília (UnB).

Assim, a UnB repensa e reestrutura-se na organização para atender esse grupo bastante diferenciado, que, apesar de todos serem inseridos à categoria indígena, nem sempre se identificam em um mesmo padrão, pois apresentam grandes diversidades linguísticas e culturais. Quanto ao aspecto linguístico, parte desse novo grupo nem sempre domina a língua portuguesa, uma vez que a ampla maioria cursou a Educação Básica em terra indígena. Sendo assim, há também situações em que a língua de instrução é a materna e não o português, que como língua não materna, não se destaca em importância ou necessidade para a comunidade que apresenta poucos falantes.

Como direito do cidadão indígena, no artigo $1^{\circ}$ da Portaria Interministerial № 559 , de 16.04/1991, é garantida a Educação Básica laica e diferenciada às comunidades indígenas. Estabelece ainda o reconhecimento de suas organizações sociais, que sejam respeitados e fortalecidos os seus processos de aprendizagem, suas tradições, costumes e línguas (BRASIL, 1991).

Da mesma forma, a política linguística para os povos originários está amparada pelo Decreto 5051 de 2004, que garante e assegura o ensino em língua materna indígena ou na língua mais comumente falada pelo grupo. No mesmo decreto, é 
afirmado que deverão ser asseguradas formas para que possibilitem o domínio da língua nacional ou de umas das línguas oficiais do país (BRASIL, 2004).

Apesar de todo amparo legal, na prática, a ampliação da política linguística não tem sido verificada de maneira totalmente efetiva e, de acordo com Gersen Baniwa, nas escolas indígenas, precisam ser levados a sério os saberes, os modos de vida e as dimensões bilíngues ou multilíngues e interculturais porque são continuidade histórica desses povos (LUCIANO, 2017).

Cabe aqui destacar que o uso da língua materna para instrução possibilita maior integração da comunidade, assim como preservação de sua própria cultura. $O$ contexto analisado neste artigo trata-se da necessidade de uso da língua portuguesa para fora dos limites das comunidades indígenas. Ela ganha importância para esses povos quando ocorre a saída de seus territórios e, por uma questão de sobrevivência, se veem obrigados a se comunicar em português, quando então surgem os conflitos e muitas vezes até mesmo confrontos culturais. Com este trabalho, o que se pretende é amenizar essa situação, possibilitando um aprendizado da língua portuguesa de uma forma menos agressiva, com atendimento diferenciado, conforme proposto no artigo $1^{\circ} \mathrm{da}$ Portaria Interministerial № 559, de 16.04/1991. Alguns dos estudantes ingressantes na UnB participantes desta pesquisa não tinham fluência na língua portuguesa, pois tiveram contatos somente na escola e de forma pouco expressiva, sobretudo os da região amazônica que, em parte, nunca haviam saído de suas terras e não conheciam sequer a sede do município em que estavam localizadas suas comunidades.

No ambiente universitário, esses estudantes enfrentam uma série de problemas adaptativos, dentre eles as dificuldades com a língua, apresentando semelhanças entre si devido à deficiência e precariedade na Educação Básica de origem. Tanto os estudantes que receberam formação bilíngue quanto os monolíngues em língua portuguesa demonstraram não ter domínio do português, principalmente na leitura, interpretação e escrita.

Segundo Euzebio e Rebouças (2017), os problemas apresentados pelos estudantes indígenas vão desde a autocrítica negativa quanto ao domínio da língua portuguesa, o que afeta na produção textual, até sua exclusão por discriminação étnica. Os mesmos autores apontam ainda outros desajustes que comprometem o processo adaptativo às universidades, como separação dos familiares, complexidade de inserção acadêmica, incapacidade e indiferença no acolhimento do acadêmico indígena, problemas financeiros e problemas de moradia.

Assim, surge a necessidade de desenvolver estratégias para o ensino do português como forma de integração ao ambiente acadêmico, com a institucionalização do Projeto Contínuo de Ensino de Português na Perspectiva de Língua de Acolhimento Indígena.

A Língua de Acolhimento, como foi proposta, tem sido usada no contexto migratório de povos estrangeiros que se encontram em vulnerabilidade e que foram forçados a sair de suas pátrias por situações adversas, como perseguição política, religiosa, catástrofes ambientais, conflitos armados entre outros. Apesar de os estudantes indígenas deste estudo não terem sofrido especificamente essas agressões, são incluídos neste contexto, uma vez que também são deslocados de suas terras de 
EUZEBIO, U.

origem por motivos outros, mas que não deixam de ser agressivos e/ou traumáticos ou por questão de sobrevivência, tornando-os também vulneráveis. $O$ ensino de português como Língua de Acolhimento para Indígenas se justifica ao pensarmos que convicções “[...] e práticas pedagógicas são repensadas e reformuladas à medida que se manifestam novas demandas socioculturais." (EUZEBIO; REBOUÇAS; LOPES, 2018, p. 59).

Nas falas dos próprios acadêmicos indígenas da UnB, a seguir, foi relatado que o indígena se sente excluído em seu próprio país, pois é estigmatizado, inferiorizado e sempre indagado sobre o porquê de não ter domínio da língua portuguesa.

"Se vocês não sabem português, como podem se considerar brasileiros?" (estudante indígena 1, entrevista, agosto 2015); "Mas você não é brasileiro? Então por que fala português dessa forma?" (estudante indígena 2, entrevista, agosto 2015); "Mas como brasileiro, você deveria falar português!' (estudante indígena 3, entrevista, agosto 2015).

Com essas ocorrências podemos perceber o quanto a nossa sociedade ainda está aquém daquela de apresentar conhecimentos e sensibilidade para compreender que não temos uma única língua no país. Certamente essa postura da sociedade está ligada ao fato de termos tido uma educação eurocêntrica e excludente em relação aos indígenas por muito tempo, que somente ganham espaço a partir da Constituição Federal de 1988, quando os povos originários passaram a receber tratamento mais inclusivo. Ainda com relação à Língua de Acolhimento, a percepção do indígena como um estrangeiro fica mais evidenciada ao observarmos que na maior parte das vezes, ao serem indagados quanto ao seu pertencimento e/ou nacionalidade, a resposta imediata se remete à própria etnia e não especificamente ao Brasil. Sendo assim, os povos indígenas são relegados a uma categoria comparável à do estrangeiro estigmatizado e em situação de vulnerabilidade que entrou no país não por opção, mas por falta dela para permanecer em suas terras de origem, portanto, uma migração forçada.

Dessa maneira, o projeto criado foi além do ensino de português, também teve o objetivo de contribuir com a formação de profissionais, professores de língua portuguesa, na concepção de Língua de Acolhimento para o atendimento de povos indígenas como um todo e não apenas aos universitários. Com essa prática, busca-se formar professores sensíveis para o atendimento de indígenas, particularmente àqueles que se encontram em situação de vulnerabilidade social, econômica e cultural, fora de seus territórios originais.

Para se conceber a abordagem de acolhimento é imprescindível compreender que Língua de Acolhimento é um conceito que difere dos demais, pois:

[...] geralmente está ligado ao contexto de acolhimento, expressão que se associa ao contexto migratório, mas que, sendo geralmente um público adulto, aprende o português não como língua veicular de outras disciplinas, mas por diferentes necessidades contextuais, ligadas muitas vezes à resolução de questões de sobrevivência urgentes, em que a língua de acolhimento tem de ser o elo de interação afetivo (bidirecional) como primeira forma de integração (na imersão linguística) para uma plena cidadania democrática (GROSSO, 2010, p. 74).

Inter-Ação, Goiânia, v.46, n.2, p. 793-809, maio/ago. 2021. Disponível em: <http://dx.doi.org/10.5216/ia.v46i2.65167>. 
O objetivo do estudo foi analisar e refletir sobre a formação de professores para ensino de Português como Língua de Acolhimento no contexto indígena tendo como referencial o respectivo Projeto Contínuo de Ensino de Português na Perspectiva de Língua de Acolhimento Indígena. Como objetivos específicos, foram levantados aspectos sobre o processo migratório, vulnerabilidade, cultura e costumes indígenas, assim como as particularidades de cada povo representado no projeto. $O$ estudo dos autores em questão tem como objetivo as condições de refugiados e grupos indígenas para sustentar a prática e o uso da Língua de Acolhimento para indígenas.

\section{LÍNGUA DE ACOLHIMENTO E SUA IDENTIDADE}

No estudo de língua não materna aparecem diferentes conceitos, como segunda língua, terceira língua, língua estrangeira, língua de herança, língua adicional e Língua de Acolhimento. $O$ objetivo deste trabalho não foi de conceituar ou distinguir essas diferentes formas de língua não materna, porém, no caso de língua adicional, dependendo da interpretação, pode haver alguma sobreposição e, portanto, foi necessário acrescentar considerações sobre essa definição.

Como o conceito de língua adicional apresenta maior aproximação com o de Língua de Acolhimento, foram necessárias algumas justificativas para o uso deste segundo em detrimento do primeiro. Para a língua adicional, os autores não são unânimes em suas definições. Rottava $(2009$, p. 85$)$ destaca que "a obtenção de L3 ou LE adicional tem a vantagem de que os aprendizes já tiveram contato ou acesso, no mínimo, a dois outros sistemas linguísticos, caracterizando-lhes como aprendizes mais experientes em relação à aprendizagem de línguas". A autora chama a atenção para o fato de que a $L 3$ ou língua estrangeira adicional diferencia-se do bilinguismo, pois, nesse caso, o aprendiz já passou pela aquisição de LE/L2.

Em um trabalho sobre conceitos de língua estrangeira, língua segunda, língua adicional, língua de herança, língua franca e língua transnacional, Souto, Além, Brito e Bernardo (2014, p. 894) apresentam a definição de língua adicional: "[...] também chamada de L3 ou língua estrangeira adicional, é, na verdade, uma terceira língua aprendida pelo indivíduo". Essas autoras citam estudos realizados de forma meticulosa sobre língua adicional por Klein (1995), Herdina e Jessner (2000) e Munoz (2002); fazem menção também a Rottava (2009) sobre L3 ou LE adicional em contexto multilíngue e De Angelis (2007) sobre aquisição de terceira língua ou língua adicional.

Por outro lado, Schlatter e Garcez (2009) se referem à língua estrangeira curricular como língua adicional, no caso específico de espanhol e inglês, justificando que essas línguas acrescentam aos que se ocupam delas, constituem-se da cidadania contemporânea, pois fazem a interlocução no mundo atual. Os autores afirmam que são línguas úteis entre nós, não são estranhas, não são "estrangeiras" e convidam professores e estudantes a refletiram sobre isso, pensarem nos papeis dessas línguas, quem é essa língua adicional, para que ela serve e a quem ela pode servir e qual a relação de cada um com ela. Nota-se aqui que não há uma definição no sentido direto, como nos autores anteriores. 
Já Leffa e Irala (2014) justificam a adequação do uso de Língua Adicional por já possuirmos uma língua, no entanto, alguns estudantes podem ter outras línguas e, assim, "[...] a língua que ele vai estudar na escola pode não ser uma segunda língua ou uma língua estrangeira, mas será, mais adequadamente, uma língua que podemos chamar de 'adicional'" (LEFFA; IRALA, 2014, p. 32).

Aprender a língua daquele que o recebe é uma necessidade e um requisito fundamental para que possa ocorrer integração à nova sociedade. "O domínio da língua é um dos fatores fundamentais na integração do refugiado, principalmente pelo fato de a barreira linguística condicionar severamente o acesso a qualquer outro aspecto referente à sua sobrevivência" (PEREIRA, 2017, p. 125).

Para Grosso (2010), não importa qual foi o motivo do processo migratório, tanto familiar quanto político, econômico ou outro, ao chegar ao novo ambiente, necessita-se imediatamente de autonomia linguística. Ninguém, nesse contexto, deixa seu ambiente de conforto espontaneamente, mas sim por questão de sobrevivência e melhoria de vida, e isso afeta o indivíduo como um todo, principalmente com relação ao trabalho.

Ao nos referirmos às definições de Língua de Acolhimento, devemos compreender o processo de recepção ao novo ambiente, no entanto isso não significa que o novo país acolhe, mas sim que simplesmente recebe, uma vez que esse processo migratório não é voluntário, mas uma condição para ambas as partes envolvidas.

A necessidade do aprendizado da nova língua é condição para a inserção, integração que atua como facilitadora para o convívio no espaço em que se está imerso. Sendo assim, há forte relação de imposição de dominador-dominado, pois não é um aprendizado pacífico e nem tampouco tranquilo, uma vez que aprender a nova língua é uma questão de sobrevivência. Diferentemente de um contexto migratório opcional e voluntário, em relação à Língua de Acolhimento o aprendiz não optou por aprendê-la e em muitos casos ocorre inclusive a recusa a esse aprendizado. Assim, é necessário compreender que não se trata de opção, "[...] a perspectiva de rejeição, de conflito e de tensão terá que ser considerada em todo o processo de ensino-aprendizagem: no planejamento, na elaboração do material didático, na avaliação e sobretudo na formação de professores [...]" (BARBOSA; RUANO, 2016, p. 325-326)

Ao abordarem o tema, Barbosa e São Bernardo (2017) chamam a atenção para o prisma emocional e subjetivo da aprendizagem da língua receptora, considerando a relação conflituosa e vulnerável do aprendiz no novo ambiente. Para as autoras, o conceito de Língua de Acolhimento reconhece haver rejeição do aprendiz com relação à aquisição de uma língua que não foi uma opção para aprender, mas uma necessidade.

É a necessidade comunicacional que vai exigir o aprendizado da língua receptora em uma sociedade que nem sempre é acolhedora, portanto, a Língua de Acolhimento é um processo, é um conjunto de medidas utilizadas como estratégias para ensinar a língua do país receptor de forma menos impositiva e menos traumática ao indivíduo que foi deslocado de sua região de origem.

O processo de ensino e aprendizagem da Língua de Acolhimento está direcionado para a integração do aprendiz à sociedade e os conteúdos envolvem temáticas do seu cotidiano, portanto, dominar a língua “[...] permite não só a comunicação com o outro, evitando dessa forma o isolamento, como também a ter acesso a melhores condições de vida, passando por uma melhor inserção no mercado de trabalho" (CABETE, 2010, p. 109). 
O ensino de português como Língua de Acolhimento não apresenta as mesmas características do português como língua estrangeira, isso porque o aprendiz pertence a um grupo visto como indesejado pela sociedade e, segundo Pereira (2017), sofre preconceito étnico da população por o julgar e por desconhecerem os motivos que o levaram a migrar.

A Língua de Acolhimento está muito além do que apenas um conceito de língua estrangeira ou de segunda língua, pois "para o público-adulto, recém-imerso numa realidade linguístico-cultural não vivenciada antes, o uso da língua estará ligado a um diversificado saber, saber fazer, a novas tarefas linguístico-comunicativas que devem ser realizadas na língua-alvo" (GROSSO, 2010, p. 68).

Em nossa sociedade, sobretudo com relação ao indígena urbano, é comum observarmos o comportamento das pessoas ao encará-lo como alguém digno de caridade e não de cidadania e direitos, sendo estigmatizados por seus aspectos físicos e comportamentais. Da mesma forma, ao se referir aos refugiados com rótulos, a população que os recebe cria estigmas de perigoso, coitado ou de despreparado, levando-os a apagar sua própria identidade pela substituição de outra, virtual, que esconde os seus verdadeiros atributos (PEREIRA, 2017).

Falar sobre a aprendizagem de uma língua significa também oportunizar e criar competências para se estabelecer o processo comunicativo entre os cidadãos, assim, a formação de professores voltados para esse tipo de aluno exige posturas diferenciadas, pois, de acordo com Barbosa e São Bernardo (2017), o professor promove maior aproximação entre o aprendente e a língua e medeia sua integração com a sociedade por meio do material didático.

Diante do exposto, considera-se que a essência da Língua de Acolhimento é a prática para atender às necessidades do cotidiano de alguém oriundo de um processo migratório em busca de melhores condições e que se encontra em situação de vulnerabilidade. Assim, a proposta de adoção da Língua de Acolhimento para indígenas com formação diferenciada de professores tem como fundamentação o fato de que indígenas e refugiados se encontram em situação de vulnerabilidade, constituem uma população em deslocamento e, nesse contexto linguístico, o aprendizado do português nem sempre é desejado. Segundo Barbosa e São Bernardo (2017), a língua adicional está volta para um contexto mais estável de opção por aprendizado da língua, com um alunado proveniente de um processo formativo mais sólido e consistente.

\section{A LICENCIATURA E A PRÁTICA PARA A FORMAÇÃO DOCENTE}

A licenciatura é fundamental no processo formativo docente, porém, tornar-se educador é um desempenho construtivo de interações múltiplas muito mais amplo, pois deve estar sempre em consonância com o contexto social em que estamos inseridos. Assim, a ampla dimensão social interpõe-se entre o saber, o educador e o educando, que juntos influenciam e são influenciados, constroem e desconstroem, modificam e são modicados, para então tornarem-se protagonistas de sua história e de sua cultura.

Porém, tudo isso se apresenta como um paradoxo, pois ao mesmo tempo em que se incentiva essa formação por amparos legais, torna-se um processo deficiente 
quando se volta para o contexto social, em que a própria sociedade se manifesta desacreditada no sistema. Para além dessa operação, ainda se esbarra em realidades nas quais as próprias instituições, que teoricamente seriam as formadoras, muitas vezes não estão engajadas e compromissadas com a qualidade da formação docente. Houve mudanças nesses valores, e isso sob a influência neoliberalista, em que instituições de ensino, especialmente as privadas, adotam práticas estritamente comerciais a ponto de encontrarmos, em alguns portais, anúncios de cursos EaD e a utilização de carrinhos de compras, como se a educação fosse um produto de venda.

Por outro lado, a educação ainda tem o seu lugar; em um estudo sobre o currículo de letras e a formação docente na perspectiva fenomenológica, Bueno (2020, p. 506) afirma que a inter e transdisciplinaridade nos leva para mudanças no campo educacional "[...] em prol de uma educação mais humana em totalidade/individualidade, integral, que considere a globalidade e a especificidade de cada sociedade".

Não há concepção de licenciatura sem envolvimento com a Educação Básica e desta com a sociedade, que tem suas demandas e exigências; portanto, os currículos para a formação decente necessitam ser adequados ao contexto em que são demandados pela coletividade. Assim, Souza (2020) expressa que deve haver um diálogo constante com a realidade para a construção do currículo: "[...] é legítimo afirmar que um currículo é tanto mais eficiente quanto for a sua capacidade de incluir e trabalhar com as muitas diferenças sociais, culturais e econômicas presentes em cada configuração educativa específica" (SOUZA, 2020, p. 13).

As políticas educacionais mais recentes têm sido duras e intransigentes e muitas vezes contraditórias aos anseios das entidades e instituições educacionais,

\begin{abstract}
[...] a base nacional comum curricular tramitou no CNE de forma não transparente e foi aprovada desconsiderando a construção já produzida pelas instituições educacionais comprometidas com a educação pública de qualidade social e sob forte resistência de três conselheiras, representantes de entidades nacionais, que votaram contra a BNCC, assim como diversas instituições e associações de docentes e pesquisadores manifestaram sua oposição a BNCC. A aprovação de uma política pública de forma antidemocrática, sem transparência e sem ampla discussão com a sociedade brasileira revela o modus operandi dos sujeitos individuais e coletivos que fazem parte, tanto de instituições consideradas públicas, quanto privadas (PERONI; CAETANO; ARELARO, 2019, p. 43).
\end{abstract}

É necessário que pensemos nesses aspectos, uma vez que estamos formando professores que irão atuar na Educação Básica e que, portanto, necessitam de uma formação íntegra, crítica e humana. A prática para a formação docente interdisciplinar para indígenas pautada em português, Língua de Acolhimento Indígena, tem por finalidade atender às necessidades imediatas para comunicação em língua portuguesa dos estudantes indígenas. Para Grosso (2010), o cenário linguístico e culturalmente diversificado e a grande mobilidade humana têm como consequência a visão de diferentes formas da educação aplicada ao estudo de línguas.

Porém, essa atuação não se limita apenas aos indígenas adultos da universidade, pois muitas das etnias Fulni-ô, Tuxá, Kariri-Xocó e Guajajara residem na Terra Indígena Santuário Sagrado dos Pajés - Pajé Santxie Tapuya, no Setor Noroeste de 
Brasília. Dessa terra, a maioria das crianças está matriculada na Escola Classe 115 Norte, cujas atividades do projeto são de apoio aos professores e de atendimento a acompanhamento desses alunos indígenas, especialmente os Guajajara que falam muito pouco o português.

O grupo de trabalho do projeto está constituído por estudantes indígenas e não indígenas na condição de extensionista e estagiário de diferentes áreas, com predominância do curso de licenciatura em Letras - Português do Brasil como segunda língua, pois a maior parte deles cursava concomitantemente a disciplina Estágio Supervisionado em língua não materna. Portanto, destaco a importância da formação interlinguística e intercultural, pois, como afirma Ançã (2008, p. 83): “É evidente que o resto, ou seja, quase tudo, fica para solucionar nas mãos dos professores, sobretudo os de LP, que nem sempre terão tido na sua formação académica uma componente interlinguística e intercultural que lhes permita lidar com a diversidade".

As observações e as práticas desse estágio supervisionado são executadas nesse projeto, pois, para Amado (2013), conhecimentos linguísticos e extra linguísticos devem ser considerados em Língua de Acolhimento e isso deve ser adquirido na formação dos cursos de letras. Amado (2013, p. 17) destaca ainda que "[...] é premente que as universidades, principalmente as públicas, que ministram cursos de Letras, criem programas de extensão universitária e incentivem seus alunos a fazerem estágios nesses programas". A autora alerta as instituições que já atuam na formação em PLE que "[...] é mais do que urgente que voltem seus olhos, na pesquisa e no ensino, a esse público que, arrancado de sua terra natal, de sua família, de sua língua, busca neste país uma nova oportunidade de refazimento, de integração, de paz..." (AMADO, 2013, p. 17).

A dinâmica do grupo consiste em dois encontros semanais, cada um com duas horas de duração: no primeiro, com o objeto de discutir, socializar, criar estratégias, preparar e avaliar as práticas; o segundo, para aplicar as atividades. Essa prática está em consonância com a Resolução CNE/CP n. 2 de 2015 que pauta sobre a participação e organização das atividades envolvendo "[...] planejamento, desenvolvimento, coordenação, acompanhamento e avaliação de projetos, do ensino, das dinâmicas pedagógicas e experiências educativas" (BRASIL, 2015).

As atividades são dinâmicas com discussões sobre o contexto indígena de cada etnia envolvida, em que o representante da etnia apresenta suas culturas e tradições, pois:

[...] vivemos hoje importantes movimentos de revitalização de identidades, línguas e culturas, em busca da história própria, narrada e tecida a partir dos povos indígenas, e que subjaz às práticas educativas, aos modos de lidar com o mundo, de conhecêlo, de habitá-lo. Podemos então dizer que se aprende a ser branco (PEIXOTO, 2020, p. 166).

A inclusão de indígenas na equipe tem como finalidade proporcionar troca de saberes como forma de ampliação de conhecimentos para que os futuros professores possam trabalhar na perspectiva de acolhimento. Devemos ampliar informações para o 
EUZEBIO, U.

conhecimento da cultura e a educação indígena para o professor em formação, sendo assim, sobre a educação Kaingang, duas pesquisadoras relatam que:

[...] é o movimento que agrega os professores, os mestres e sábios da cultura para repensar a escola, produzi-la de forma dialógica com os saberes e conhecimentos ancestrais, como está sendo realizado no programa de formação continuada Saberes Indígenas na Escola, que em seu desenrolar mostra visivelmente um processo descolonial, ou pelo menos que fuja do modelo tutelar instituído pelo Estado brasileiro na relação com os povos indígenas (BERGAMIASCHI; ANTUNES, 2020, p. 121).

A finalidade principal é desenvolver a produção textual oral, uma vez que a Língua de Acolhimento atua no desenvolvimento de habilidades para o atendimento das necessidades imediatas. Assim, "o ensino da língua está muito centrado nas necessidades do quotidiano, em que na maioria dos casos, a oralidade predomina, seria natural que no processo de ensino-aprendizagem a compreensão e a expressão orais também fossem contempladas" (CABETE, 2010, p. 110). Para a produção escrita ocorrem outras atividades paralelas com acompanhamentos específicos.

$\mathrm{Na}$ Escola Classe 115 Norte as atividades são quinzenais com o mesmo objetivo e dinâmica, porém com participação dos professores e coordenadores. Além do ensino de português, essas atividades têm como finalidade estimular os futuros professores para a percepção do seu papel de educador, pois a formação docente:

\footnotetext{
[...] deve assegurar a base comum nacional, pautada pela concepção de educação como processo emancipatório e permanente, bem como pelo reconhecimento da especificidade do trabalho docente, que conduz à práxis como expressão da articulação entre teoria e prática e à exigência de que se leve em conta a realidade dos ambientes das instituições educativas da educação básica e da profissão, para que se possa conduzir o(a) egresso(a): I - à integração e interdisciplinaridade curricular, dando significado e relevância aos conhecimentos e vivência da realidade social e cultural, consoantes às exigências da educação básica e da educação superior para o exercício da cidadania e qualificação para o trabalho; II - à construção do conhecimento, valorizando a pesquisa e a extensão como princípios pedagógicos essenciais ao exercício e aprimoramento do profissional do magistério e ao aperfeiçoamento da prática educativa (BRASIL, 2015).
}

Dessa forma, para que seja uma proposta ativa, interdisciplinar, é necessário conhecer a realidade do aluno, o contexto em que está inserido, além do espaço destinado ao trabalho. Assim, para que ocorra ensino e aprendizagem deve haver sensibilidade e planejamento pelo docente, pois "o planejamento de curso em nível macro precisa prever a capacitação do corpo docente [...], exigindo-se sensibilidade para a realidade contextual da turma e do próprio ensino de português como língua de acolhimento" (LOPES; REBOUÇAS; EUZEBIO, 2019, p. 172).

Em sua dissertação de mestrado sobre Língua de Acolhimento, Cabete (2010) destaca a importância dessa formação que contribui para a preparação do futuro 
professor, não apenas conhecedor do ensino de língua não materna, mas com habilidades no ensino para o público adulto.

Todas as atividades, ações e decisões do projeto foram coletivas, assim como as práticas, que foram de responsabilidade de todo o grupo, uma vez que ocorreu uma construção conjunta.

\section{CONSTRUÇÃO METODOLÓGICA, REFLEXIVA E AVALIATIVA}

A concepção do Projeto teve como princípios a abordagem interdisciplinar participativa com 17 estudantes indígenas de 11 etnias e 23 não indígenas, que em meio a esta "[...] constelação de línguas, culturas, etnias e interacções entre elas, é a LP que destacamos, e que entendemos de acolhimento, no seu sentido literal (refúgio, casa, forte)" (ANÇÃ, 2008, p. 84).

Os estudantes indígenas, a maioria "bilingues", apresentavam grandes dificuldades de comunicação em língua portuguesa, tanto na oralidade quanto na escrita. Por outro lado, os monolíngues, em português, apesar de se comunicarem oralmente na "variante indígena", como dizem, também apresentaram muitas dificuldades em leitura, interpretação e expressão escrita.

Este trabalho é um recorte investigativo e avaliativo de ação do Projeto por dois anos, com dados obtidos a partir de observações embasadas na Pesquisa-Ação, seguindo a metodologia adaptada da Escuta Sensível de Barbier (2007). Os dados foram obtidos a partir de registro de atas das reuniões semanais e de um diário de campo com relatos e percepções do grupo.

Para as atividades preparativas, foram discutidos os processos de construção de textos orais a partir da realidade de cada etnia. Nos temas trabalhados, representantes de cada etnia optaram por fazer apresentações sobre costumes, língua e tradições de seus povos. Dessa forma, podemos compreender que a competência comunicativa baseada no conhecimento sociocultural e sociolinguístico abre diálogos para a cidadania plena e consciente, fundamental na língua de acolhimento (GROSSO, 2010).

Para isso, houve inicialmente a seleção do conteúdo pelos respectivos representantes, quando então procedeu-se à teorização para a construção dos textos (MARCUSCHI, 2008; KOCH; ELIAS, 2012; KOCH, 2014).

Todo o processo de construção textual, quanto à questão lexical, sintática, semântica e pragmática utilizadas na construção e apresentação de um texto oral, foi subsidiado com orientação e apoio da equipe de estagiários. Dessa forma, ocorre interrelações e trocas de saberes entre os grupos indígena e não indígena, licenciandos e não licenciandos, caminhando lado a lado para uma profissionalização mais concreta e mais coerente, pois:

[...] a língua de acolhimento tem um saber fazer que contribui para uma interação real, a vida cotidiana, as condições de vida, as convenções sociais e outras que só podem ser compreendidas numa relação bidirecional. A história de vida no passado e no presente abre um leque de hipóteses em que ensinante $e$ aprendente cooperam e aprendem juntos, ultrapassam as questões 
EUZEBIO, U.

do quotidiano, integram-se pelo bem-estar, pela confiança, e isso só pode ser alcançado pela língua de acolhimento (GROSSO, 2010, p. 71).

Pelo fato de serem indígenas e, teoricamente, não serem imigrantes, não significa que os temas trabalhados estejam desconectados da realidade, pois, segundo Grosso (2010), atividades interculturais baseadas em situação problema são significativas para o desenvolvimento das competências gerais e comunicativas desse público.

As reflexões estão pautadas na preparação e apresentação, mostrando apenas parte da grande diversidade cultural existente entre os povos indígenas. Porém, foi enriquecedor e significativo para o conhecimento de futuros professores da área.

Nas práticas apresentadas, os povos Atikum, Potiguara e Kariri-Xocó expuseram o significado do toré, dança cujo objetivo é agregar e socializar esses povos, porém, para os povos da Amazônia, apesar de também praticarem a dança, não tem o mesmo significado, sendo uma prática mais reservada a cada etnia. Os Atikum apresentaram ainda a planta jurema, destacando sua importância nos rituais; por outro lado, os KaririXocó também apresentam uma variante do ritual secreto Ouricuri. Esse ritual é bem característico e altamente significativo como identidade do povo Fulni-ô, que também apresentou as características básicas de sua língua la-tê, intimamente ligada ao ritual do Ouricuri, a única língua viva ainda mantida por povos indígenas do nordeste. O ritual do Ouricuri, tanto para os Fulni-ô como para os Kariri-Xocó, apesar de apresentarem algumas diferenças, é sigiloso e mantido em segredo por ambas as etnias.

Quanto ao povo Iny-Karajá, como são chamados, apresentaram sobre o Hetohoky, os segredos dos espíritos na casa grande Iny-Karajá, que é:

\begin{abstract}
A expressão cultural mais forte dos Iny-Karajá é o ritual de representação dos seres cosmológicos do povo Hetohoky quando os worosy, entes espirituais, 'visitam' o Hawã, o pessoal, durante as festividades. As manifestações possuem caráter de religiosidade e de iniciação dos wevry, os meninos ao mundo adulto. (EUZEBIO; SILVA, 2017, p. 35, grifo dos autores).
\end{abstract}

O povo Karipuna promoveu uma ampla discussão sobre Kheuól, falado pelos povos do Amapá com influências do francês e do português, utilizado pelos mais velhos no ambiente familiar, nos rituais religiosos e na escola, mas "os Karipuna utilizam mais o português no dia a dia, proporcionando, consequentemente, maiores espaços de interação com a língua" (CARVALHO, 2018, p. 12).

O povo Kaxuyana apresentou as características de sua língua e do seu sistema numérico, em que se conta somente até três, o restante, a partir desse número, são nomeados como muitos, uma característica cultural desse povo que também se apresentou contrário à lei Maria da Penha, com a justificativa de quem faz justiça interna é o próprio povo e não o branco.

Sobre o povo Macuxi de Roraima, foram apresentadas as formas de manifestações de curas pelos pajés, identificando como são as revelações para que seja designado um pajé: não é por escolha, nem indicação, mas por revelação própria, mesmo muito tempo após a morte do seu antecessor. 
O povo Baré discutiu a questão do ensino e aprendizagem na sua concepção, em que se aprende por observação e não por explanação; caso o aprendiz tenha dúvida, ele pergunta aos mais velhos, porém tudo se dá a partir de observação dos mais velhos. Não há um momento específico de se ensinar, mas se aprende na prática do dia a dia. Não preservam uma língua original, mas usam desde os tempos históricos a língua nheengatu.

No caso do povo Kokama, cuja língua está sendo resgatada, há também o resgate do ritual de passagem do menino para a vida adulta, prática da comunidade indígena de Sapotal no Alto Solimões do estado do Amazonas.

Quanto ao povo Tikuna, foi apresentado o significado do ritual da moça nova, oficina de cestos e artefatos de palha de palmeiras, conceitos básicos de sua língua, falada por todos, inclusive língua de instrução da educação básica.

A partir das discussões, observações, leituras, análise das atas e análise dos depoimentos, pode ser verificado que essa prática contribuiu para o desenvolvimento da língua oral, tanto dos universitários como dos próprios indígenas da Educação Básica, apesar que nesse caso não houve atividade tão regrada como para acadêmicos da universidade. Quanto aos estudantes estagiários, em seus depoimentos foram enfáticos ao dizer que a prática promoveu aprendizado e fundamentação para a atuação como professores em Língua de Acolhimento Indígena. Por se tratar de um recorte, este trabalho terá continuidade para que se possa ter maior exploração dos dados obtidos e assim contribuir com a literatura sobre Língua de Acolhimento.

Quanto às particularidades do ensino de português como Língua de Acolhimento para indígenas, está o fato de que esses povos, mesmo inseridos no país, ao migrarem para fora de seu ambiente são expostos à condição de vulnerabilidade. Assim, o aprendizado da língua portuguesa é uma condição de sobrevivência não apenas para a obtenção de emprego, mas também para serem aceitos socialmente no novo ambiente. Esses dados estão em conformidade com a afirmação de Grosso (2010), que os associa ao contexto migratório, público adulto, aprendizado de português que muitas vezes está ligado às questão urgentes de sobrevivência que se constituem no elo afetivo de integração do aprendiz.

Os povos originários culturalmente apresentam características em seus costumes que muitas vezes não se enquadram nos contextos urbanos de convívios com não indígenas. Um estudante indígena participante do projeto, em uma de suas falas, afirma que "o índio existe no coletivo", o que é um fator muito mais forte do que o individual, sendo assim, ao se pensar no ensino de língua, deve-se incluir esse significado de coletividade existente no contexto indígena.

Outro aspecto está no fato de que falar português nem sempre significa que o indígena domine a língua escrita, mesmo sendo universitário, a Língua de Acolhimento, que consiste em uma abordagem que prioriza o atendimento diferenciado com pessoas em situação de vulnerabilidade, objetiva amenizar o aprendizado para a efetivação do processo comunicativo.

\section{CONCLUSÃO}


A formação de professores de português voltada para a Língua de Acolhimento Indígena deve ir além da estruturação de uma disciplina, por meio de projetos que possam ampliar conhecimentos teóricos e práticos para a área.

A participação de estudantes indígenas na construção da prática contribuiu para que os formandos tivessem acesso a informações enriquecedoras que provavelmente jamais teriam adquirido somente com teoria.

É importante o desenvolvimento de atividades conjuntas de planejamento e análise de resultados como forma de avançar no processo de ensino e aprendizagem. Ao final do estudo de análise e reflexão, foi constatado que iniciativas participativas contribuem para a formação de professores para Ensino de Português como Língua de Acolhimento Indígena.

Tanto estudantes indígenas como não indígenas tiveram motivação para desempenhar os respectivos papeis, demonstrando que a motivação e a contextualização superam os obstáculos encontrados no início da atividade.

Artigo recebido em: 20/08/2020

Aprovado para publicação em: 30/12/2020

TEACHING TRAINING IN PORTUGUESE, INDIGENOUS HOST LANGUAGE: ASPECTS AND PARTICULARITIES FOR PEOPLE ORIGINATING IN BRAZIL

ABSTRACT: The host language is characterized by being inserted in the migratory context, making the link between the affective and the integration of people in vulnerability for emergency learning. As a theoretical basis this work is based on (ANÇÃ, 2008; GROSSO, 2010; CABETE, 2010, AMADO, 2013; BARABOSA; SÃO BERNARDO, 2017). The objective was to analyze and reflect on the training of teachers for Teaching Portuguese as an Indigenous Host Language and to verify the adequacy of this terminology from na extension Project with indigenous and non-indigenous students. Barbier's sensitive listening methodology (2007) was applied and as a result, practices aimed at indigenous peoples make it possible to adapt the term for this use, since teh indigenous condition is adequate and this context.

KEYWORDS: Indigenous. L2. Teacher Training. Portuguese.

ENSEÑANZA DE LA FORMACIÓN EN PORTUGUÉS LENGUA DE ACOGIDA INDÍGENA: ASPECTOS Y PARTICULARIDADES PARA PERSONAS ORIGINARIAS EN BRASIL

RESUMEN: La lengua de acogida se caracteriza por estar insertada en el contexto migratorio, haciendo el vínculo entre lo afectivo y la integración de personas en vulnerabilidad para el aprendizaje de emergencia. Como base teórica se basa este trabajo (ANÇÃ, 2008; GROSSO, 2010; CABETE, 2010, AMADO, 2013; BARABOSA; SÃO BERNARDO, 2017). El objetivo fue analizar y reflexionar sobre la formación de profesores para la Enseñanza del Portugués como Lengua de Acogida Indígena y verificar la adecuación de esa terminología a partir de un Proyecto de Extensión com estudiantes indígenas y no indígenas. Se aplicó la metodología de escucha sensible 
de Barbier (2007) y como resultado, las prácticas dirigidas a los pueblos indígenas permiten adecuar el término para este uso, ya que la condición indígena es adecuada y este contexto.

PALABRAS CLAVE: Indígena. L2. Formación de Profesores. Portugués.

\section{REFERÊNCIAS}

AMADO, R. de S. O ensino de português como língua de acolhimento para refugiados. Revista SIPLE, Brasília, v. 4, n. 2, p. 11-18, 2013.

ANÇÃ, M. H. S. F. Língua portuguesa em novos públicos. Saber (e) Educar, Porto, n. 13, p. 71-87, 2008. Disponível em:

$<$ http://repositorio.esepf.pt/bitstream/20.500.11796/924/2/SeE_13LinguaPortuguesa.pd f>. Acesso em: 16 ago. 2020.

BARBIER, R. A pesquisa-ação. Tradução de Lucie Didio. Brasília: Líber Livro, 2007. 159p.

BARBOSA, L. M. de A.; RUANO, B. P. Acolhimento, sentidos e práticas de ensino de português para migrantes e refugiados, na Universidade de Brasília e Universidade Federal do Paraná. In: GEDIEL, J. A. P.; GODOY, G. G. (org.). Refúgio e hospitalidade. Curitiba: Kaiorós, 2016. p. 321-336.

BARBOSA, L. M. de A.; SÃO BERNARDO, M. A. de. Língua de acolhimento. In: CAVALCANTI, Leonardo et al. Dicionário crítico de migrações internacionais. Brasília: Editora Universidade de Brasília, 2017. p. 434-437.

BERGAMASCHI, M. A.; ANTUNES, C. P. Professores indígenas no Sul do Brasil: dos contextos de dominação/ submissão aos caminhos da autonomia. Foro de Educación, $\begin{array}{lllllll}\text { Dortmund-Germany, } \quad \text { v. 18, n. 1, p. 103-124, } 2020 . & \text { DOI: }\end{array}$ http://dx.doi.org/10.14516/fde.692

BRASIL. Ministério da Justiça. Portaria interministerial MJ/MEC $\mathrm{N} \bullet 559$, de 16.04.91. Cria a Coordenação Nacional de Educação Indígena e dá providências correlatas. Disponível em: <http://portal.mj.gov.br/main.asp?View=\{5992FBDB-9FC7-495D-929EB53947CBE4C1\}>. Acesso em: 16 jul. 2020.

BRASIL. Presidência da República. Decreto n. 5051, de 19 de abril de 2004. Promulga a Convenção no 169 da Organização Internacional do Trabalho - OIT sobre Povos Indígenas e Tribais. Disponível em:

<https://www.planalto.gov.br/ccivil_03/_Ato2004-2006/2004/Decreto/D5051.htm>. Acesso em: 18 ago. 2020. 
EUZEBIO, U.

BRASIL. Conselho Nacional Educação. Resolução CNE/CP n. 2, de $1^{\circ}$ de julho de 2015. Define as Diretrizes Curriculares Nacionais para a formação inicial em nível superior (cursos de licenciatura, cursos de formação pedagógica para graduados e cursos de segunda licenciatura) e para a formação continuada. Brasília: CNE, 2015. Disponível em: $<$ http://portal.mec.gov.br/index.php?option=com_docman\&view=download\&alias=704 31-res-cne-cp-002-03072015-pdf\&Itemid=30192 >. Acesso em: 20 jul. 2020.

BUENO, E. R. de A. Formação docente na perspectiva fenomenológica e do pensamento complexo: reverberações acerca do currículo de uma graduação em letras. Humanidades \& Inovação, Palmas, v. 7, n. 8, p. 494-508, 2020.

CABETE. M. A. C. S. da S. O processo de ensino-aprendizagem do português enquanto língua de acolhimento. 2010. Dissertação (Mestrado em língua e cultura portuguesa) - Faculdade de Letras, Universidade de Lisboa, Lisboa, 2010. Disponível em: http://repositorio.ul.pt/bitstream/10451/4090/1/ulfl081236_tm.pdf. Acesso em: 08 nov. 2018.

CARVALHO, A. C. O bilinguismo em aldeias Galibi-Marworno e Karipuna. Revista Brasileira de Línguas Indígenas, Macapá, v. 1, n. 2, p. 5-18, 2018.

EUZEBIO, U.; REBOUÇAS, E. M. Inserção de estudantes indígenas na universidade pública brasileira a partir da produção textual. Raído, Dourados-MS, v. 11, n. 27, p. 507-528, jul./dez. 2017. DOI: 10.30612/raido.v11i27.5660

EUZEBIO, U.; REBOUÇAS, E. M.; LOPES, L. P. S. Política Língua de acolhimento: demandas e perspectivas subjacentes ao conceito e à prática pedagógica do no contexto brasileiro. In: GUIMARÃES, D. N.; ANDRÉ, B. P. (org.) Educação e diversidade: diálogo intercultural. Campos do Goytacazes: Brasil Multicultural, 2018. p. 58-87.

EUZEBIO, U.; SILVA, W. P. da. Educação e cultura indígena: traços do segredo em cosmologias Fulni-ô, Kariri-Xocó e Iny-Karajá. In: GUIMARÃES, D. N.; AMARAL, S. C. de S. (org.) Educação, cultura e sociedade: diálogos interdisciplinares. Campos do Goytacazes: Brasil Multicultural, 2017. p. 24-39.

GROSSO, M. J. R. dos. Língua de acolhimento, língua de integração. Horizontes de Linguística Aplicada, Brasília, v. 9, n.2, p. 61-77, 2010. DOI:10.26512/rhla.v9i2.886.

HERDINA, P; JESSNER, U. The dynamics of third language acquisition. In: CENOZ, J; JESSNER, $U$ (ed.). English in Europe: the acquisition of a third language. Clevedon, UK: Multilingual Matters, 2000. p. 84-98.

KLEIN, E. C. Second versus third language acquisition: is there a difference? Language Learning, v. 45, n. 3, p. 419-465, set. 1995. DOI: https://doi.org/10.1111/j.14671770.1995.tb00448.x

KOCH, I. V. As tramas do texto. 2. ed. São Paulo: Contexto, 2014. 
KOCH, I. V.; ELIAS, V. M. Ler e escrever: estratégias de produção textual. 2. ed. São Paulo: Contexto, 2012.

LEFFA, V. J.; IRALA, V. B. O ensino de outra(s) língua(s) na contemporaneidade: questões conceituais e metodológicas. In. LEFFA, V. J.; IRALA, V. B. (org.). Uma espiadinha na sala de aula: ensinando línguas adicionais no Brasil. 1. ed. Pelotas: Educat, 2014, v. 1, p. 21-48

LOPES, L. P. S.; REBOUÇAS, E. M.; EUZEBIO, U. Política linguística em contexto de imigração e refúgio: o planejamento do ensino de português como língua de acolhimento no âmbito do Distrito Federal. Muiraquitã, Rio Branco, v. 7, n. 2, 2019, p. 162-179. DOI:https://doi.org/10.29327/212070.7.2-13

LUCIANO, G. J. S. dos._Língua, educação e interculturalidade na perspectiva indígena. $\mathbf{R}$. Educ. Públ., Cuiabá, v. 26, n. 62/1, p. 295-310, 2017.

DOI: 10.29286/rep.v26i62/1.4996

MARCUSCHI, L. A. Produção textual, análise de gêneros e compreensão. São Paulo: Parábola, 2008.

MUÑOZ, C. Bilingualism and trilingualism in school students in Catalonia. In: CENOZ, J; JESSNER, $U$ (ed.). English in Europe: the acquisition of a third language. Clevedon, UK: Multilingual Matters, 2000. P. 157-178.

PEIXOTO, L. F. Aprendendo com a Amazônia. Revista Teias, Rio de Janeiro, v. 21, n. 61, p. 150-167, 2020. DOI: https://doi.org/10.12957/teias.2020.49706

PEREIRA, G. F. O português como língua de acolhimento e interação: a busca pela autonomia por pessoas em situação de refúgio no Brasil. Cadernos de Pós-Graduação em Letras, São Paulo, v. 17, n. 1, p. 118-134, 2017. DOI 10.5935/cadernosletras.v17n1p118-134

PERONI, V. M. V.; CAETANO, M. R.; ARELARO, L. R. G. BNCC: disputa pela qualidade ou submissão da educação? RBPAE, Goiânia, v. 35, n. 1, p. 35 - 56, 2019. DOI: https://doi.org/10.21573/vol31n22015.61726.

ROTTAVA, L. Português como língua terceira (L3) ou língua estrangeira (LE) adicional: a voz do aprendiz indicando identidade. Em Aberto, Brasília, v. 22, n. 81, p. 81-98, ago. 2009.

SCHLATTER, M.; GARCEZ, P. Línguas adicionais (Espanhol e Inglês). In: RIO GRANDE DO SUL. Secretaria de Estado da Educação. Departamento Pedagógico. Referenciais curriculares do Estado do Rio Grande do Sul: linguagens, códigos e suas tecnologias. Porto Alegre: SEERS, p. 125-172, 2009. 
EUZEBIO, U

SOUTO, M. V. L.; ALÉM, A. O. F. G.; BRITO, A. M. de S.; BERNARDO, C. Conceitos de língua estrangeira, língua segunda, língua adicional, língua de herança, língua franca e língua transnacional. Revista Philologus, Rio de Janeiro, v. 20, n. 60, p. 890-900, set./dez. 2014. Disponível em: <www.filologia.org.br/revista/60sup.html $>$. Acesso em: 04 jan. 2021.

SOUZA, R. A. do C. Descolonização e resistência: a UNILAB e a formação de professores de história para o Brasil e a África. Anos 90, Porto Alegre, v. 27, e2020006, p. 1-14, 2020. DOI: 10.22456/1983-201X.86578 0.

Umberto Euzebio: Professor Doutor da Universidade de Braślia, graduado em Biologia, Letras e Pedagogia, credenciado nos Programas de Pós-Graduação em Desenvolvimento, Sociedade e Cooperação Internacional (Mestrado e Doutorado) e em Ensino de Biologia - PROFBIO (Mestrado) na área Interdisciplinar em Desenvolvimento e Políticas Públicas para o Ensino a Refugiados e Indígenas, Língua de Acolhimento, Educação e Ensino bilíngue de Ciências, Biologia para Indígenas e Refugiados, Letramento Científico e Metodologia de Ensino para Jovens e Adultos.

Orcid: https://orcid.org/0000-0002-2492-7383

E-mail: umbertoeuz@gmail.com

Este periódico utiliza a licença Creative Commons Attribution 3.0, para periódicos de acesso aberto (Open Archives Initiative - OAI). 